\title{
Screening for sexually transmitted disease in London-based male prostitutes
}

\author{
D R Tomlinson, R J Hillman, J R W Harris, D Taylor-Robinson
}

\begin{abstract}
Objective-To provide a screening service for sexually transmissible infections to male prostitutes working in the London area.

Design-An open access service recruiting by a diverse range of methods to avoid overrepresentation of the more visible elements of this group.

Setting-Department of genitourinary medicine in a London teaching hospital and a community-based clinic at a safe address.

Results-During the 10 months following the establishment of the service in June 1990, 57 male prostitutes (38 street based and 19 "escorts") were seen. Of these, 27 men (47\%) were found to have evidence of such an infection. Twenty five per cent of the street-based men had serological evidence of previous infection with hepatitis B virus (HBV), $6 \%$ had positive syphilis serology, $9 \%$ had non-gonococcal urethritis (NGU), $18 \%$ had urethral and $13 \%$ rectal gonorrhoea. None had gonorrhoea at more than one site. Twenty-seven per cent of these men were HIV 1-antibody positive. Thirty-seven per cent of the escorts had serological evidence of previous infection with HBV, none had positive syphilis serology, $11 \%$ had NGU, $5 \%$ had urethral and $8 \%$ rectal gonorrhoea. None had gonorrhoea at more than one site. Twenty-five per cent of these men were HIV 1-antibody positive.

Conclusion-Specific targeting of resources at this group of individuals is necessary to promote better health education and use of health care provisions.
\end{abstract}

The Department of Genitourinary Medicine, Jefieriss Wing, St. Mary's Hospital, London W2 1NY

D R Tomlinson, R J Hillman, J R W Harris, D TaylorRobinson

Clinical Research Centre, Watford Road, Harrow, Middlesex HA1 3UJ, UK

R J Hillman, D Taylor-Robinson
Introduction

Male prostitution is illegal in most societies and its essentially covert nature makes it poorly recognised and little understood. Whilst anecdotal references exist from Roman times through to the present day, ${ }^{1}$ there are few scientific data available. As this group of men engages in a large number of sexual encounters, it is postulated that they may be at high risk of acquiring, and spreading, sexually transmissible agents, including the Human Immunodeficiency Virus (HIV). ${ }^{2}$ To investigate this hypothesis, we established a health care service targeted specifically at men selling sex in the London area and the preliminary findings from the first 10 months are reported here.

\section{Methods}

Three methods of recruitment were used to gain access to this heterogeneous group of men: (1) a weekly informal clinic held at an agency involved in outreach work with street-based male prostitutes (socalled "rent boys"); (2) regular advertising of the health service in both the weekly and monthly gay press; and (3) "cold calling" (making direct telephone contact) of men advertising themselves as escorts or masseurs in the gay press. Soon after establishing this service these recruitment tactics were supplemented by respondents bringing in their colleagues.

Data were collected on age, duration of prostitutional activities prior to initial consultation, number of paying partners per week, expressed sexual orientation and condom usage. Following discussion, the men themselves chose which screening tests they wanted performed from the battery of tests offered. This meant that some men had only a serological test for hepatitis B markers, whereas others undertook the complete screen. It must be stressed that facilities at the outreach agency day-centre were very basic and little other than serological tests could be offered in this situation. Hence the data are not complete on all the prostitutes.

Urethral and rectal smears were stained using the Gram method and more than 10 polymorphonuclear leucocytes per high-power field was taken as evidence 
of non-gonococcal urethritis (NGU) or non-gonococcal proctitis (NGP). Swabs from the urethra, pharynx and rectum were plated directly onto a selective medium for isolation of Neisseria gonorrhoeae. Chlamydia trachomatis was sought in the urethra using both immunofluorescence (MicroTrak) and ELISA (Chlamydiazyme) tests. Rectal swabs were taken and placed into viral transport medium for herpes simplex (HSV) culture. The serological tests used for syphilis were the Venereal Disease Research Laboratory (VDRL) test, the Treponema pallidum haemagglutination assay (TPHA) and the Fluorescent treponemal antibody absorption (FTA) test. Tests for hepatitis B virus (HBV) were those for hepatitis B surface antigen (HBSAg), anti-core IgM antibodies (IgM anti-HBc) and antibodies to HBSAg (HBSAb). After obtaining informed consent, some of the men were tested for HIV 1and 2 antibody and p24 antigen (Wellcome and Abbott ELISA).

\section{Results}

Fifty-seven men were interviewed over a 10-month period and underwent screening for sexually transmissible agents. Of these men, 38 were street-based rent boys and 19 were men who advertised themselves as "escorts" or "masseurs".

\section{Rent boys}

Twenty eight of the $38(74 \%)$ rent boys regarded themselves as homosexual in orientation, four $(11 \%)$ as heterosexual, five $(13 \%)$ as bisexual and one $(2 \%)$ declined to answer that question. Age at initial consultation ranged from 17 to 26 years, with a mean age of 19.7 years, and a mode and a median both of 19 years. Of the 34 men who gave information about the duration of prostitutional activities, $18(52 \%)$ had been involved for 12 months or less, six $(18 \%)$ for between 13 and 24 months, five (15\%) between 25 and 36 months, two $(6 \%)$ for between 37 and 48 months, one (3\%) for between 49 and 60 months and two $(6 \%)$ for more than 60 months (table 1). Twenty three men reported five or fewer paying partners per week, 10 six to 10 partners, one 11-15 partners, none 16-20, one 21-30 and three declined to answer (table 2).

Details of the results of the investigations undertaken on this group of men are presented in table 3. Thirty two men were screened for serological markers of HBV. Three had a past history of intravenous drug use, seven were currently using intravenous drugs and 22 had never used intravenous drugs. None of those screened were shown to carry HBSAg. However, eight (25\%) had detectable HBSAb and anti-HBc, indicative of a naturally acquired infection. Only two of these men had used, or were currently using, intravenous drugs. None were found
Table 1 Duration of prostitution at initial visit

\begin{tabular}{lll}
\hline $\begin{array}{l}\text { Duration of } \\
\text { prostitution } \\
\text { (months) }\end{array}$ & $\begin{array}{l}\text { Rent boys } \\
(n=34)\end{array}$ & $\begin{array}{l}\text { Escorts/Masseurs } \\
(n=19)\end{array}$ \\
\hline$<6$ & 9 & 7 \\
$6-12$ & 9 & 5 \\
$13-24$ & 6 & 4 \\
$25-36$ & 5 & 0 \\
$37-48$ & 2 & 0 \\
$49-60$ & 1 & 3 \\
$>60$ & 2 & 0 \\
\hline
\end{tabular}

to be IgM anti-HBc positive only. Sixteen men $(42 \%)$ were tested for serological markers of syphilis and one was positive, with a VDRL titre of $1 / 8$ and strongly positive TPHA and FTA tests. This man had no history of previous infection or treatment. Eleven men underwent testing for HIV. Three of these were HIV 1-antibody positive, one of whom underwent sero-conversion during the study. Two men had perianal condyloma acuminata. $N$ gonorrhoeae was isolated from two of 11 urethral swabs and one of eight $(13 \%)$ rectal swabs but from none of nine pharyngeal swabs. No man had $N$ gonorrhoeae isolated from more than one anatomical site. NGU was found in one of the 11 men and in no case was $C$ trachomatis detected. None of eight rectal swabs was positive for HSV.

\section{Escorts/Masseurs}

Of 19 men seen, $10(53 \%)$ described themselves as escorts, eight $(42 \%)$ as masseurs and one $(5 \%)$ as a stripper. Four of these men had legitimate full-time day jobs and supplemented their income on a parttime basis by prostitutional activities. Sixteen men $(84 \%)$ described their sexual orientation as homosexual and three $(16 \%)$ as bisexual. None described himself as heterosexual. Age range at presentation was 17 to 39 years, with a mean of 25.4 years, a mode and a median of 24 years. Twelve of the 19 men $(63 \%)$ had been involved in prostitutional activities for 12 months or less, four $(21 \%$ ) for 13 to 24 months and three $(16 \%)$ between 25 and 60 months (table 1 ). Five reported five or fewer paying partners per week, five six to 10 partners, four $11-15$, none $16-20$, and three 21-30 (table 2). Two men declined to answer this question.

Table 2 Number of paying partners reported per week

\begin{tabular}{lll}
\hline $\begin{array}{l}\text { Reported } \\
\text { number paying } \\
\text { partners/week }\end{array}$ & $\begin{array}{l}\text { Rent boys } \\
(n=35)\end{array}$ & $\begin{array}{l}\text { Escorts/Masseurs } \\
(n=17)\end{array}$ \\
\hline$<5$ & 23 & 5 \\
$6-10$ & 10 & 5 \\
$11-15$ & 1 & 4 \\
$16-20$ & 0 & 0 \\
$21-30$ & 1 & 3 \\
\hline
\end{tabular}


Table 3 Results of screening tests undertaken on rent boys and on escorts/masseurs

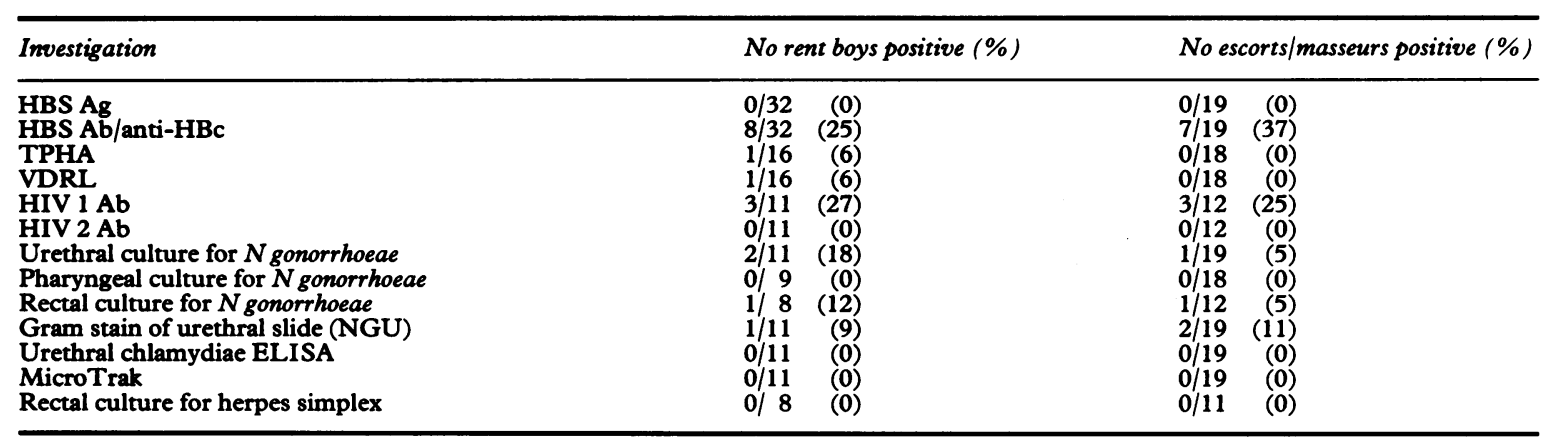

Details of the results of the investigations performed on this group of men are also presented in table 3. All the men were tested for $\mathrm{HBV}$ serological markers. None had used, or were using, intravenous drugs. Seven of the $19(37 \%)$ were found to possess HBSAb. Twelve men $(63 \%)$ had no detectable serological marker present, including IgM anti-HBc. Eighteen were tested for serological evidence of syphilis, all with a negative result. Three of 12 men $(25 \%)$ tested for HIV were HIV 1-antibody positive but none had detectable p24 antigen. $N$ gonorrhoeae was isolated from the urethra of one of the 19 men $(5 \%)$, and from the rectum of another man (one of 12 men tested $(8 \%)$ ). None of the 18 pharyngeal cultures was positive for $N$ gonorrhoeae. Two of the 19 men $(11 \%)$ had NGU and five $(26 \%)$ had perianal condylomata acuminata. None of 12 rectal HSV cultures was positive.

Fifty of the men interviewed gave information about condom usage for anal intercourse. Thirty eight $(76 \%)$ reported the use of condoms "usually" or "always" with paying partners, whereas only 14 $(28 \%)$ used condoms to the same degree with nonpaying partners.

\section{Discussion}

The illegal and taboo nature of prostitution renders data collection from this group of individuals difficult and this is particularly true of male prostitutes. The number of male prostitutes is unknown, their sexual practices little understood and their susceptibility to infection not documented. The data presented here, although incomplete, are the only ones available on male prostitutes in the United Kingdom. Twenty seven $(47 \%)$ of the prostitutes in this study had evidence of a sexually transmissible disease (STD) or infection, comprising $14(37 \%)$ of the 38 street-based rent boys and $13(68 \%)$ of the 19 escorts/masseurs.

Hepatitis $B$ vaccination has been offered to all those with no serological evidence of previous infection, the intention being to reduce the spread of this potentially fatal infection within this group of men and their sexual partners.

Our data probably underestimate the prevalence of STD in the street-based male prostitute group, as only $16(42 \%)$ of the 38 men had any investigations other than a test for HBV serological markers. Only eight $(21 \%)$ of this group of men were fully investigated. This was primarily due to the lack of facilities for full screening and did not reflect safer sexual practices by this group. Hence, statistical tests of possible differences between the two groups are not appropriate as the completeness of the screening tests undertaken was very different.

The large proportion $(68 \%)$ of the escorts and masseurs with evidence of an STD may, of course, be due to a selection bias towards those men actively seeking screening because of symptoms or of suspicion of having put themselves at risk of infection.

Twelve of the $19(63 \%)$ escorts requested full STD screening, providing the most complete data from which to determine prevalence rates. A small sub-group of these men has been attending for regular screening and the data they provide should allow us eventually to estimate incidence rates for STDs in this group.

It is unclear whether these individuals would have used existing services if our service had not been available. Symptomatic infections such as acute urethral gonorrhoea would presumably lead to individuals seeking treatment but asymptomatic infections would not. Rectal gonorrhoea, for example, may remain asymptomatic and provide an important reservoir of infection in such individuals. It is only through appropriate health education that we can raise awareness of such issues in this group of men.

The data presented here may be compared with the results of studies of male prostitutes by others. Coutinho et $a l l^{3}$ from The Netherlands, found prevalence rates of $26 \%$ and $42 \%$ for syphilis and HBV seromarkers, respectively. These compare with rates of $15.3 \%$ and $56.7 \%$ respectively for female prostitutes reported from Greece. ${ }^{4}$ The results of 
American studies have been slightly different, with $58 \%$ of street-based male prostitutes having positive serological tests for $\mathrm{HBV}$ and $22 \%$ positive serological tests for syphilis."

Positive HIV antibody tests for $26 \%$ of the men (rent boys and "escorts" combined), in our study, is a prevalence figure similar to that reported for streetbased male prostitutes in the USA $(27 \%)^{5}$ and South America $(33 \%){ }^{6}$ This figure is two to three times greater than that reported for the transvestite male prostitutes in Italy $(11 \%)^{7}$ and for Coutinho's sample of prostitutes in The Netherlands $(13 \%){ }^{3}$ It is unclear to what extent these differences reflect a sampling bias but by using four different recruitment tactics we have tried as far as possible to obtain a representative sample.

We have observed that male prostitutes are more likely to claim to use condoms and adopt "safer sex" practices with paying partners (76\%) than nonpaying partners $(29 \%)$, like their female counterparts. ${ }^{8}$ It must be remembered that self-reported condom usage may be unreliable and respondents may give the answer that they feel is acceptable to the investigator, particularly in a face-to-face interview. However, given this observation, the risks of acquiring sexually transmissible infections may, therefore, be related not to prostitution per se, but to the noncommercial sexual practices of the prostitutes. The dynamics of the situation may, however, be altered by clients demanding, and being prepared to pay higher prices, for high-risk sex.

\section{Conclusions}

The high prevalence of STDs $(47 \%)$ shown in the male prostitutes in this study supports the suggestion that male prostitutes may be important in the transmission of sexually acquired infection. The overall prevalence rate of HIV infection (26\%) leads us to suggest that specific targeting of resources at this high risk group to promote better health education might empower these individuals to protect themselves, their clients and hence the community at large, from all sexually transmissible agents.

We gratefully acknowledge the financial support of the Jefferiss Trust which made this work possible.

\section{Address correspondence to Dr DR Tomlinson.}

1 Davies PM, Simpson PJ. On the Contemporary Forms of Male Homosexual Prostitution in London. Social Research Unit. University of Cardiff, 1986.

2 Hillman RJ, Tomlinson DR, Taylor-Robinson D, Harris JRW. Male prostitution and sexually transmitted diseases. Int $J$ STD AIDS 1990;1:245-9.

3 Coutinho RA, van Andel RLM, Rijsdijk TJ. Role of male prostitutes in spread of sexually transmitted diseases and human immunodeficiency virus. Genitourin Med 1988;64: 207-8.

4 Papaevangelou G, . Trichopoulos D, Kremastinou T, Papoutsakis G. Prevalence of Hepatitis B antigen and antibody in prostitutes. $B M J 1974 ; 1: 256-8$.

5 Elifson K, Boles J, Sweat M. Risk factors for HIV infection among male prostitutes in Atlanta. Abstract WAP 38; Vth International Conference on AIDS, Montreal 1989.

6 Cortes E, Detels R, Slamon D, Aboulafia D, Li XI, Ho D. Seroprevalence of HIV 1, HIV 2 and HTLV 1 in Brazilian bisexual males. Abstract MGP14; Vth International Conference on AIDS, Montreal 1989.

7 Tirelli U, Vaccher E, Bullian P, et al. HIV-1 seroprevalence in male prostitutes in north-east Italy. J Acquir Immun Def Synd 1988;1:414-5.

8 Day S, Ward H, Harris JRW. Prostitute women and public health. $B M J 1988 ; 297: 1585$.

Accepted for publication 8 January 1991 